\title{
Knowledge Management, Absorptive Capacity and Organizational Culture: A Case Study from Chinese SMEs
}

Weifeng Chen, Tally Hatzakis

Brunel Business School, Brunel University, Uxbridge, UK, UB8 3PH

Weifeng.Chen@brunel.ac.uk

Tally.Hatzakis@brunel.ac.uk

\begin{abstract}
Based on the analysis of an innovative medium sized enterprise from mainland China, this paper investigated the knowledge management (KM) issues by focusing on its $\mathrm{KM}$ enablers and process. This paper attempts to investigate how Chinese enterprises absorb knowledge from external sources; how they developed culture to facilitate knowledge management processes; and what major challenges they raise for the future by looking at the case study of a Chinese SMEs (Small and Medium-sized Enterprises). The case study indicates that Chinese enterprises emphasized knowledge acquisition and the capacities of knowledge absorption, application, creation, sharing and integration as vital to sustaining competitive advantage for these firms. Corporative organizational culture also has significant impact on the knowledge management in those enterprises.
\end{abstract}

Keywords: Absorptive capacity, Knowledge management, Knowledge acquisition, Corporative culture, SMEs. 


\section{Introduction}

With more than 25 percent of the world's population, China promises exciting opportunities for all multinational corporations. In the last two decades, its GDP has increased more than tenfold (Ahlstrom, Bruton, and Lui, 2000), and its annual economic growth has been sustained at over 10 percent. Observers all over the world are impressed by the rapid growth of China's economy, some with hope and others with fear (Gu and Lundvall, 2006). While outside observers tend to focus on the success story of unprecedented growth, policy documents and recent domestic debates in China have pointed to the need for a shift in the growth trajectory with stronger emphasis on 'independent innovation' and 'harmonious development' (Gu and Lundvall, 2006). Chinese Small and Medium-sized Enterprises (SMEs) have conducted a series of radical and successful restructuring under government policies. In particular, some of those SMEs have exhibited substantial innovation capabilities in building greater competitive advantage. This paper attempts to investigate how Chinese SMEs absorb knowledge from external sources; how they have developed a culture that facilitates knowledge management processes; and what major challenges they raise for the future by looking at the case study of a Chinese SMEs (Jiangsu Farun)

In most industries, the conventional belief is that companies that possess greater technological and innovative capacity have higher competitiveness than those without this capacity. In general, firms from emerging economies are usually in a disadvantageous position to compete in the global market since they lack technological capacity (Makino and Lau, 1998). In emerging economies like China, firms generally face difficulties with acquiring advanced technological knowledge from external sources for three main reasons. First, as compared to developed countries, there exist few industrial clusters where knowledge-intensive firms operate in close geographical proximity. Firms in emerging economies therefore tend to have a disadvantage in accessing knowledge spillovers and knowledge workers. Second, in emerging economies there exist few well-developed networks of manufacturing and distribution through which firms could capitalise on acquired technological knowledge for both production and commercial application in a local market. Third, since in most emerging economies legal protection of intellectual property is limited, foreign investors make technology transfer difficult (Tsui and Lau, 2002). Critical to most knowledge-intensive business enterprises based in China is how to explore the external sources of advanced technological knowledge, how to develop cultural and social contexts that facilitate both the transfer and dissemination of acquired technology across subunits within an organization, and how to turn acquired technology into commercial products or services.

\section{Theoretical Framework for This Study}

A theoretical framework based on the literature in knowledge management process and critical organizational factors is proposed in this study. Nevis et al. (1995) proposed three knowledge management processes; acquisition, dissemination, and utilization. Knowledge acquisition means the development or creation of skills, insights, and relationships. Knowledge dissemination means the dissemination of what has been learned. Utilization means the integration of learning so it is broadly available and can be generalized to new situations. Leonard (1995) identified factors leading to a "core rigidity" in relation to changes that limit a firm's capacity to develop new knowledge. Pfeffer and Sutton (2000) also warned about the discrepancy 
between knowing and doing. The literature suggests that firms must develop a certain organizational arrangement in order to enhance knowledge creation and change. This arrangement broadly includes structural design, organizational culture, information-processing capability and processes, and human resource systems (Huber, 1991; Van den Bosch, Volberda, and Boer, 1999; Whittington, Pettigrew, Peck, Fenton, and Conyon, 1999). Specifically, Tushman (1977) suggested the importance of the role of boundary-spanning individuals in acquiring external knowledge and disseminating knowledge within a firm. Gupta and Govindarajan (2000a, 2000b) examined the relationship of parent companies and overseas subsidiaries in a knowledge-sharing context and noted the importance of incentives for individuals in a firm to share knowledge. De Long and Fahey (2000) also noted that a certain organizational culture is needed for knowledge creation, sharing, and use. The organizational arrangement examined in the literature therefore ranges from individual-level incentives and boundary-spanning roles to the broader culture of an organization. Hence, the literature suggests that a certain organizational arrangement is conducive to effective knowledge acquisition and dissemination.

In knowledge acquisition and transfer, absorptive capacity plays a critical role. Cohen and Levinthal (1990) defined absorptive capacity as prior-related knowledge, including knowledge of the most recent scientific or technological developments, that confers an ability to recognise the value of new information, assimilate it, and apply it to commercial ends. Underlying the notion that absorptive capacity is a function of prior-related knowledge is the idea that knowledge acquisition is most effective when the target knowledge is related to what is already known, and it is the most difficult in novel domains (Cohen and Levinthal, 1990). That is, acquisition of new knowledge from external sources tends to be more successful when a firm possesses existing knowledge related to the new knowledge being acquired. And, internal transfer of the acquired knowledge tends to be more efficient when the recipient unit of the firm possesses prior knowledge related to the knowledge being transferred. Several researchers (Hamel, 1991; Inkpen, 2000; Lyles and Salk, 1996) have focused on the ability of firms to learn and they have suggested that the effectiveness of learning between organizational units is closely related to Cohen and Levinthal's (1990) notion of absorptive capacity.

As one of the key organizational factors that impact on knowledge management, organizational culture is essential for successful knowledge management (Davenport et al., 1998; Demarest, 1997; Gold et al., 2001). A survey by Chase (1998) indicates that 80 percent of the people who participated in the survey recognise that culture is the most important factor for creating a knowledge-based organization. Culture is a basic building block to knowledge management. It must be considered when introducing knowledge management because it affects how an organization accepts and fosters knowledge management initiatives. If knowledge management is to be an integrated aspect of how work gets done in an organization, it must become an integrated aspect of the culture (Ndlela and Toit, 2001). Culture defines not only what knowledge is valued, but also what knowledge must be kept inside the organization for sustained innovative advantage (Long, 1997). Creating a knowledge-friendly culture is one of the most critical factors of success for a knowledge management (Ndlela and Toit, 2001; Davenport and Prusak, 1998). Organizations should establish an appropriate culture that encourages people to 
create and share knowledge within an organization (Holsapple and Joshi, 2001; Leonard, 1995).

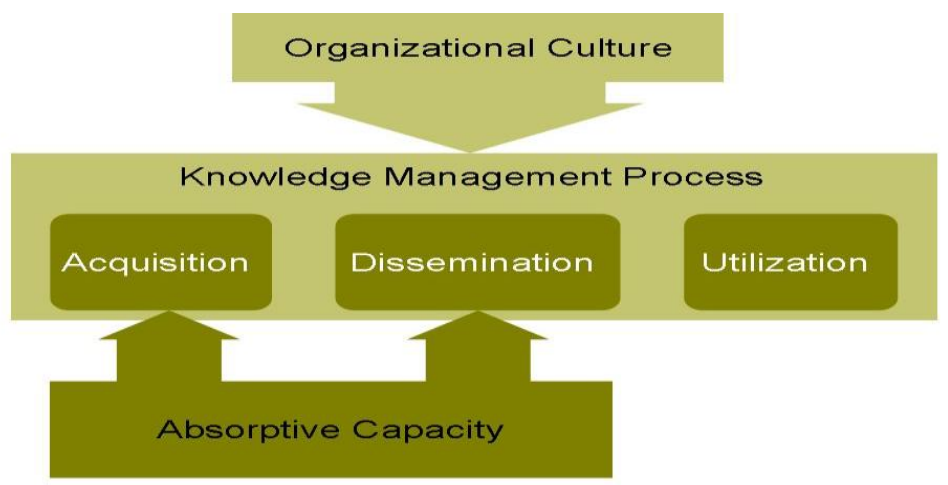

Figure 1: Theoretical Framework for KMP in Chinese SMEs

The above discussion suggests several major features of firms that will facilitate the knowledge acquisition, dissemination, and utilization process. Figure 1 shows a schematic model that depicts the links among the supportive mechanisms, critical organizational factors, and the knowledge management process. The model is primarily based on current literature. However, in the case of Chinese SMEs, higher reliance on institutional support is expected. For example, firms can seek institutional support for gaining legitimacy and competitive advantage, and they can acquire strategic resources through their parent firms in most state-owned enterprises (SOEs). These resources include social capital and absorptive capacity. At the organizational arrangement level firms can develop flexible structures, skills- and performance-based reward systems, and innovative group culture to enhance competitiveness. This new organizational form, in contrast to traditional SOEs, depends very much on the capability of a firm's top management team or leadership to integrate resources and develop the appropriate culture. The theoretical framework is used to guide our analysis of the knowledge management process (KMP) of the Chinese enterprise. The appropriateness and limitations of this framework are then discussed.

\section{Research Methods}

In recent years, there have been a growing number of research papers on knowledge management in China's SMEs. The tradition of scientific method would therefore suggest that an examination of factors that impact on knowledge management could be carried out using survey research tools. Our research is still developing and ongoing. In this instance we have chosen a single case study approach (Yin 1994) for this paper. Yin (1994) stated several circumstances to use single-case study. First, the case represents the critical case in testing a wellformulated theory. Second, the case represents an extreme or unique case. Third, the single case is the revelatory case, which is previously inaccessible to scientific investigation. Our case study on Farun is revelatory that it presented the growth of a typical Chinese SME and its change on knowledge management strategy.

There are obvious limitations in findings drawn from single case analysis such as, for instance, generalizability. However, this approach allows an in-depth analysis of the complex issues in the research topic, enabling 'The researcher to peep behind the formal aspects of organization settings' (Bryman, 1989). First, a case study method 
is especially useful when change in the research subject is still ongoing. Second, evidence from single case analysis can serve well in 'analytic generalization' (Yin, 1994). Third, we believe that Farun, the firm examined in this paper, may be representative of a relatively new group of Chinese SMEs.

\section{Data Collection and Analysis}

The data collection process was carried out in three phases over a period of 11 months. The first phase, from February 2006 to July 2006, involved collecting and reviewing secondary data from this Chinese company, and developing a literature base for the investigation's theoretical framework. These company-specific documents included annual reports, newsletters, strategic reports, press articles, and a recent review of the company history. These materials were obtained through close contact established by the researchers with managers / shareholders from the enterprise. This preliminary information collection enabled the authors to identify the key issues for the research, forming a basis for the design of the semi-structured interview.

The second phase, the first involving primary data collection, was carried out in August and September 2006 in the headquarters of the enterprise in Zhangjiagang, China. We formally interviewed 5 top managers (including the Chairman and Managing Director of the firm) and 15 middle managers from different departments of Farun. All the interviewees were involved in the knowledge management processes. Most were directly involved in the design and implementation of the establishment of the new knowledge management model in Farun. Apart from their knowledge and views on the questions asked, the interviewees were encouraged to elaborate on the process and complexities of the knowledge management experienced inside Farun. They were also invited to verify the information provided in prior interviews and clarify issues in contradiction and confusion. Participation in the interviews was voluntary with respondents given anonymity. W. Chen later translated the verified responses into English, and the quality of this translation was reviewed by a third party.

The third phase of data collection occurred after September 2006. We have maintained frequent information exchange with managers in FARUN through email and telephone. Our informants not only include managers (former interviewees) but also some middle managers. This was to fill in any gaps identified after the field visit to clarify conflicting information and to incorporate data on issues ignored during interviews in the previous stages.

To analyze the case study evidence, the strategy adopted for this study is to follow the theoretical framework proposed in Section 2 that led to the case study (Yin, 1994). Interview data and field notes were analyzed using both standard interview technique (Yin, 1994), and the 'critical incident' approach suggested by Erlandson et al. (1993). This involved recording data on milestones of Farun 's knowledge management development. These data were then structured to address the research topic. Emerging themes were then pursued to extract leads by which to understand the forces for knowledge management in Farun and the impact of organizational culture. In the case analysis, we present this evidence in a summary which is up-to-date as of November, 2006. 


\section{Case Study: Jiangsu Farun}

\subsection{Organizational Background}

Jiangsu Farun Group is a successful company with revenues of over £2 billion in 2005. It is one of the largest Chinese float glass manufacturers with an annual output of 42 million containers of float glass. The firm now has more than 400 knowledge workers. Established in 1994, Farun was a small State-Owned Enterprise (SOE) manufacturing a lower standard of glass with 50 employees at inception. It became a privately-owned enterprise in 1997. A change of management triggered the rapid growth of Farun. Starting in 2001, Farun has invested heavily in product innovation based on the import of advanced technology and new production lines from the United Kingdom, the United States, France, Germany and other countries. Constant updates in production technology and enhancement of employee skills have sustained their competitiveness in the Chinese glass market as Farun has abandoned the market for low quality glass products to move toward higher quality standard glass products and auto glass products.

During the data gathering process it became apparent that several knowledge management initiatives were underway in various Farun business units. Some had been in place for several years; others were just beginning. Noticing this phenomenon, Chen Huinan, Farun's MD and Vice President decided to attempt to facilitate knowledge management at the firm by holding a series of workshops on the topic. The idea was to bring together a diverse group of people within the company who were already engaged in knowledge management in some form or who were interested in getting started. Key objectives for the workshops included the facilitation of knowledge sharing through informal networking and the establishment of common language and management frameworks for knowledge management. In April 2005, as part of the KM strategy, Farun started a training programme with Shanghai Caizhi (a joint venture with Nanjing University, Shanghai Jiaotong University and Hong Kong Chinese University and others) to improve employee capabilities.

\subsection{Knowledge Management Processes Analysis}

At Farun four primary learning activities create and manage the knowledge necessary for its current and future operations that have internal and external foci. As Figure 2 shows, Leonard (1995) describes these activities as: (1) shared, creative problem solving (to produce current products); (2) implementing and integrating new methodologies and tools (to enhance internal operations); (3) formal and informal experimentation (to build capabilities for the future); (4) pulling in expertise from outside (externally) (Leonard,1995). 


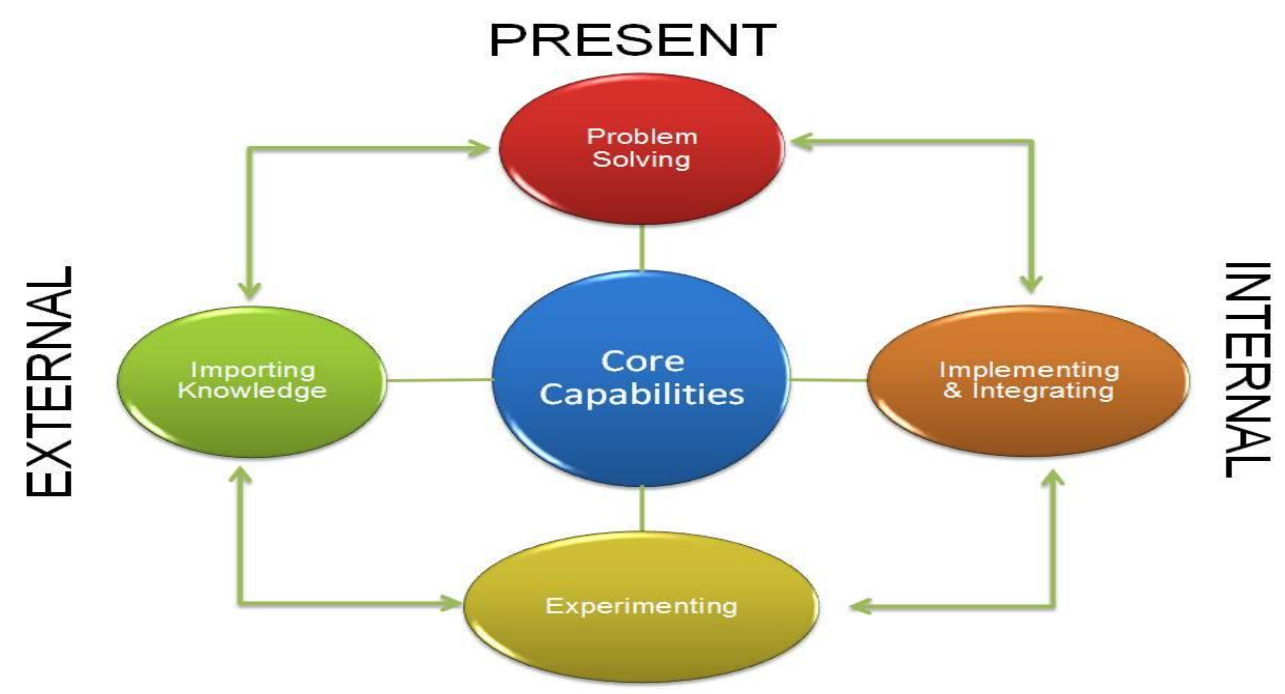

FUTURE

Figure 2: Knowledge Creating and Diffusing Activities (Leonard,1995)

As one operations manager points out, "Everyone has ideas when some problem happens. The person working on the equipment contributes a lot because they see exactly what happens... If the problem cannot be solved immediately, he can not just leave the problem as it is. He will report this problem to us. We will gather around and everyone will try to find a solution for this problem.... ". This kind of shared problem solving happens quite often in Farun. However, when the problem to be solved needs innovation, it will be a different story.

Through constantly improving production processes, Farun has created knowledge to sustain the competitiveness. They believe that innovation accompanies implementation of new tools. Some enhancements of the production processes are already novel enough to be patented. All the business units are required to meet every week to exchange their experience and discuss the problems in their work. The output of those meetings are organized and archived as the part of the organizational memory. The knowledge and ideas found in the production line and management practices are stored and organized into a knowledge database (archived by paper files). The knowledge database also is stored electronically in the company's ERP (Enterprise Resource Planning) system. Everyone can access the knowledge database under the control of the chief knowledge officer. Besides handling the business processes (i.e. finance, HR), the internet based ERP system in Farun is also a platform for employees to share their knowledge virtually. Mr Chen (MD and Vice President) told us that "The performance has been dramatically improved after introducing the ERP system in Farun..... It is much easier and quicker for employees to find the knowledge required for their work than before."

One of the operations managers also mentioned that "We don't have suggestion boxes in our company. We share all the ideas and if the idea fails, everyone shares in knowledge of the failure. We focus on the good of the whole. All the patents in our company belong to the company not individuals. ...". Product innovation requires skilled $R \& D$ researchers and ideas from production line and market analysis. Therefore, corporative culture is vital for Farun to be innovative enough to survive in the competitive market today. 
Importing and absorbing knowledge from outside the firm is one of the key factors that determine the success of Farun. Given the relative youth of the company, Farun is still in the early learning stage compared to western companies in the glass industry. Farun has invested heavily in technological knowledge through imports from developed countries (USA, UK, France, Germany, etc). As one manager from marketing department points out, "We attend lots of exhibitions in glass industry all over the world every year. When we see any new products from our competitors, we will bring those samples back and send them to our $R \& D$ department to do some research. We are trying to learn from them and catch up.... " One of the important knowledge management initiatives in Farun involves experts (consultants) from famous Chinese universities. Farun also invites these experts to give workshops or lectures to groups of employees from different departments on a regular basis to update employee knowledge and skills. As part of the expert network, Farun encourages employees to make contact with university experts.

\subsection{Analysis of Farun's Organizational Culture}

\subsubsection{Knowledge Corporative Culture}

At Farun one significant aspect of its culture are corporate knowledge practices that promote knowledge sharing. This includes use of experts at all levels of Farun's organization to encourage group problem-solving and the sharing of new ideas and knowledge.

A corporate knowledge culture is one of the important factors leading to the success of innovation projects. It is also the most difficult part to build from scratch. Despite the apparently successful implementation of the cultural change, it is important to remember that culture is not simply the conscious design of management, but reflects the evolution of the organization over a period. On the other hand, top management has been clearly proactive in changing culture within the organization. The heart of knowledge-sharing activities in Farun is a climate of continuity and trust. As a senior manager explained, "This is the most difficult aspect of knowledgesharing to achieve. If you can't do it, you can't succeed. We grew up learning to hoard knowledge to achieve power. Farun created a culture of trust encouraging active knowledge sharing across time and space among all of the company's employees....". In his view, 'the most valuable employee is the one who becomes a source of knowledge and actively shares that knowledge with other people'. The corporate knowledge culture at Farun encourages everyone to become knowledge entrepreneurs. The facilitative climate has encouraged associates to take risks, innovate and get out of the habit of asking for instructions. Knowledge entrepreneurship is rewarded (promotion, bonus money, car, etc. ), and enquiry and innovations are promoted.

\subsubsection{Role of Top Management}

Top management in Farun takes knowledge leadership seriously, insisting that 'the climate we create as leaders have a major impact on our ability to share knowledge across time and space', observed an informant. Chen Huinan recognized trust as one of the company's core values. 'For knowledge-sharing to become a reality, you have to create a climate of trust in your organization. You cannot empower someone 
that you do not trust and who does not trust you.' A code of ethics that values the individual is at the core of the learning mindset. In addition, Farun constantly reinforces lessons that provide knowledge for customer service. The aim is to deploy knowledge at the point of sale for the benefit of the customer. 'We need to invest in knowledge sharing like any other investment that will redefine an organization', he says. It is important to consider the political dimension of leadership therefore and to look at the application of rewards and sanctions to help overcome resistance. Neither culture nor leadership should be seen in a wholly uncritical manner however. With this backdrop the most important leadership role in the knowledge management arena - an ability to 'manage the managers' and to enroll them as enthusiastic practitioners of knowledge management - is enabled.

\subsubsection{Communities of Practice}

Another interesting phenomenon found in Farun is the formation of 'communities of practice'. Communities of practice have evolved informally as a means of building on the knowledge of others to problem solve. Enabled by the use of virtual communities, lessons learned have the ability of being shared throughout the firm. An engineer from the R\&D department sees these communities as "small sub-groups of people who have mutual respect, share some common values and generally get the important work done. They are not necessarily a team, a task force or any other authorized group. Their bonding is social as well as technical, and is built around informed participation."

However the sharing of knowledge outside a community is extremely hard to enforce. Many managers have great difficulty in trying to understand and build any meaningful system around this process.

\subsection{Knowledge Management Strategy}

Knowledge management is a multi-level set of technologies, norms and practices. For such qualitatively different aspects to evolve in a consistent, mutually reinforcing way, the guiding role of management is critical. In this context, arguably one of the most important elements for the effective sharing of knowledge is a clear and conscious knowledge strategy. Since 2001 Farun has consciously decided to compete on the basis of knowledge, and hence has made it a strategic priority to integrate the $\mathrm{KM}$ process with work. Anticipation of knowledge-creation and knowledge-sharing are built into the mindset of the company and all its people.

Strategic efforts are being made at Farun to ensure that every employee knows that an important part of working for the company is to learn as much as possible. The case study shows that much of the added value of changes associated with knowledge management results not from changes to the technology itself but from the new arrangements and roles of the organization, management and the people who can make the best use of technology.

It is clearly indicated therefore that knowledge management must be embedded in the processes in which people work. This case demonstrates that knowledge management is a process which facilitates knowledge creation and sharing through corporative culture and communities of practice. The company's approach is to incorporate knowledge management practices into its culture to ensure that it achieves its mission to compete on knowledge. 


\section{Conclusions}

This study examined the knowledge management process and enabling corporative culture in a medium-sized Chinese enterprise called Farun which has successfully developed from a typical SME. We found that most of the firms in China emphasized the acquisition phase of knowledge management more and stressed integration and creation less. This pattern could be due to the youth of these enterprises. They are still in the early learning stage compared to enterprises in the developed western world. This study focused on the impact of absorptive capacity and organizational culture on knowledge management processes in Chinese SMEs. We were not able to observe interactions between organizational design, absorptive capacity, and knowledge integration in building comparative advantages. For future research on SMEs in emerging economies, examination of the interplay of institutional and organizational factors with the various phases of knowledge management should be fruitful.

Our Farun case has confirmed that when the SME firms move into more competitive and more global markets, they will have to develop other value-added assets in order to sustain their competitiveness. However, this is a big challenge for Chinese SMEs. According to this, the role of government has changed in China since 1995. Government often plays the role of venture capitalist and knowledge constants. Research institutions, including universities, have also been involved in developing firms' advantages. The interactions between these parties and the corporate governance structure for knowledge integration and dissemination should be considered in future studies of the more mature Chinese SMEs.

Some Chinese SMEs have been able to grow and achieve their current leading role because of their focus on the local market and on cost advantages over other global firms. However, when an industry gets more sophisticated and the market becomes more global, these companies can no longer sustain their competitiveness. These SMEs have to develop new ventures, markets, and products. The question is how they can apply their current knowledge to obtain synergy in the new ventures. What is the mechanism needed to achieve successful integration? What types of leadership are required to sustain the competitiveness of these firms? These are the questions future studies of SMEs in China should address.

\section{References}

Bryman, A. (1989), Research Methods and Organizational Studies, London: Unwin Hyman Press.

Cohen, W. M., and Levinthal, D. A. (1990). Absorptive capacity: A new perspective on learning and innovation. Administrative Science Quarterly, 35: 128-152.

Davenport, T.H., and Prusak, L. (1998) Working Knowledge. Boston: Harvard Business School Press,.

Davenport, T.H.; Long, D.; and Beers, M.C. (Winter 1998) Successful knowledge management projects. Sloan Management Review, 43-57.

De Long, D.W., and Fahey, L. (2000). Diagnosing cultural barriers to knowledge management. Academy of Management Executive, 14(4): 113-127

Demarest, M. Understanding knowledge management. (1997) Long Range Planning, 30, 3 374-384. 
Erlandson, D. A., Harris, L., Skipper, B. L. and Allen, S. D. (1993), Doing Naturalistic Inquiry: A Guide to Methods, London: Sage

Gold, A.H.; Malhotra, A.; and Segars, A.H. (2001) Knowledge management: an organizational capabilities perspective. Journal of Management Information Systems, $18,1,185-214$.

Gu, S.; Lundvall,B. A. (2006) China's Innovation System and the Move Toward Harmonious Growth and Endogenous Innovation Innovation: Management, Policy and Practice. 8 (1)

Gupta, A. K., and Govindarajan, V. (2000a). Knowledge flows within multinational corporations. Strategic Management Journal, 21: 473-496.

Gupta, A. K., and Govindarajan, V. (2000b). Knowledge management's social dimension: Lessons from Nucor Steel. Sloan Management Review, 41 (fall): 71-80

Holsapple, C. W., and Joshi, K.D. (2001) Organizational knowledge resources. Decision Support Systems, 31, 39-54.

Huber, G.P. (1991). Organizational learning: The contributing process and the literature. Organization Science, 2: 88-115.

Leonard, D. (1995). Wellsprings of knowledge: Building and sustaining the sources of innovation. Boston: Harvard Business School Press.

Long, D.D. , (1997) Building the knowledge-based organizations: how culture drives knowledge behaviors. Working Paper of Center for Business Innovation. Ernst and Young LLP.

Makino, S., and Lau, C. M. (1998). The road to MNE of firms from newly industrialized economies. Paper presented at the Academy of Management annual meetings, San Diego.

Ndlela, L.T., and Toit, A.S.A. (2001) Establishing a knowledge management programme for competitive advantage in an enterprise. International Journal of Information Management, 21, 151-165.

Nevis, E.; Anthony, D.; and Gould, J. (Winter 1995) Understanding organizations as learning systems. Sloan Management Review, 73-85.

Pfeffer, J., and Sutton, R.I. (2000). The knowledge-doing gap: How smart companies turn knowledge into action. Boston: Harvard Business School Press.

Tsui, Anne S.; Lau, C. M. (2002) The management of enterprises in the People's Republic of China, International Economics Journals, Springer

Tushman, M.L. (1977). Special boundary roles in the innovation process. Administrative Science Quarterly, 22: 587-605.

Van den Bosch, F. A. J., Volberda, H.W., and Boer, M. (1999). Coevolution of firm absorptive capacity and knowledge environment: Organizational forms and combinative capabilities. Organization Science, 10: 551-568.

Whittington, R., Pettigrew, A., Peck, S., Fenton, E., and Conyon, M. (1999). Change and complementarities in the new competitive landscape: A European panel study, 1992-1996. Organization Science, 10: 583-600.

Yin, R. K.(1994), Case Study Research: Design and Methods, 2nd edition, London: Sage. 